\title{
Effect of creatine on aerobic and anaerobic metabolism in skeletal muscle in swimmers
}

\author{
C H Thompson, G J Kemp, A L Sanderson, R M Dixon, P Styles, D J Taylor, G K Radda
}

\begin{abstract}
Objective-To examine the effect of a relatively low dose of creatine on skeletal muscle metabolism and oxygen supply in a group of training athletes.

Methods- ${ }^{31} \mathbf{P}$ magnetic resonance and near-infrared spectroscopy were used to study calf muscle metabolism in a group of 10 female members of a university swimming team. Studies were performed before and after a six week period of training during which they took either $2 \mathrm{~g}$ creatine daily or placebo. Calf muscle metabolism and creatine/choline ratios were studied in resting muscle, during plantar flexion exercise (10-15 $\mathrm{min})$, and during recovery from exercise.

Results-There was no effect of creatine on metabolite ratios at rest or on metabolism during exercise and recovery from exercise. Muscle oxygen supply and exercise performance were not improved by creatine if compared to placebo treated subjects.

Conclusions-Oral creatine supplementation at $2 \mathrm{~g}$ daily has no effect on muscle creatine concentration, muscle oxygen supply or muscle aerobic or anaerobic metabolism during endurance exercise. (Br ₹ Sports Med 1996;30:222-225)
\end{abstract}

Key terms: creatine; magnetic resonance spectroscopy; near-infrared spectroscopy, skeletal muscle

MRC Biochemical and Clinical Magnetic Resonance Unit, John Radcliffe Hospital, Headington, Oxford, United Kingdom

$\mathrm{C} \mathrm{H}$ Thompson, clinical lecturer

G J Kemp, senior lecturer

A L Sanderson, research fellow

R M Dixon, non-clinical scientist

P Styles, senior non-clinical scientist D J Taylor, non-clinical scientist

G K Radda, professor

Correspondence to: Dr C H Thompson, MRC Magnetic Resonance Spectroscopy, John Radcliffe Hospital, Headington, Oxford OX3 9DU

Accepted for publication 19 December 1995
Creatine, principally found in skeletal muscle, participates in the reaction catalysed by creatine kinase ${ }^{1}$ :

$$
\mathrm{PCr}+\mathrm{ADP}+\mathrm{H}^{+}<=>\mathrm{ATP}+\text { creatine }
$$

This reaction is normally near-equilibrium in skeletal muscle, and has many important functions. ${ }^{1}$ It is important in buffering [ATP] against changing energy demand, ${ }^{2}$ and in determining $[A D P]$, the driving force for oxidative phosphorylation. ${ }^{3}$ Net phosphocreatine (PCr) hydrolysis provides ATP directly in the early stages of exercise. ${ }^{4}$ Operation of the reaction in the direction of net PCr hydrolysis serves to buffer protons produced in anaerobic glycolysis by lactic acid generation, ${ }^{5}$ and there is an increase in the concentration of inorganic phosphate $(\mathrm{Pi})$, which is an obligatory submitochondrial ATP synthesis. Increased levels of creatine may facilitate energy transfer between the mitochondrion and the cytosol by increasing the concentration of cytosolic $\mathrm{PCr}$, a reservoir of high energy phosphate for mitostrate for both glycogen phosphorylase ${ }^{6}$ and chondrial ATP synthesis. The ingestion of $20 \mathrm{~g}$ creatine daily for five days has been shown to increase muscle [creatine] ${ }^{7}$ and to decrease muscle fatiguability. ${ }^{8}$ It has also been proposed that creatine supplementation might increase the rate of PCr recovery following exercise. ${ }^{8}$

We used ${ }^{31} \mathrm{P}$ and ${ }^{1} \mathrm{H}$ magnetic resonance spectroscopy (MRS) to examine noninvasively the effect of a longer course of a lower dose of creatine on the constituents of the creatine kinase reaction in resting and exercising skeletal muscle in a group of athletes. We coupled the MRS studies with a study of muscle reoxygenation rate using near-infrared spectroscopy (NIRS). The study was conducted in a placebo controlled fashion and the subjects were studied before and after six weeks of either placebo or creatine treatment.

\section{Methods}

SUBJECTS

Ten non-vegetarian female athletes [lean body mass 45.7 (SEM 1.1) kg] from the university swimming team were studied by ${ }^{31} \mathrm{P}$ MRS and NIRS immediately before an eight week training period leading up to an intervarsity competition. Six weeks after the initial studies, the MRS and NIRS studies were repeated. The performance times of each subject swimming freestyle over $100 \mathrm{~m}$ and $400 \mathrm{~m}$ were recorded within one week of the MRS study.

\section{PROCEDURES}

Subjects were randomised to a six week course of either $2 \mathrm{~g}$ creatine or placebo per day; $2 \mathrm{~g}$ is the manufacturer's recommended daily dose of creatine for athletes taking Ergomax tablets (AMS Ltd, Goole, North Humberside, UK). The tablets were taken dissolved in warm water and, if possible, were taken about $30 \mathrm{~min}$ before training.

Subjects lay in a $2.0 \mathrm{~T}$ superconducting magnet (Oxford Magnet Technology, Eynsham, Oxford, UK) interfaced to a Bruker spectrometer (Coventry, UK), with the right calf overlying a $6 \mathrm{~cm}$ diameter surface coil. Spectra were acquired using a $2 \mathrm{~s}$ interpulse delay at rest (64 scans) and during exercise and recovery. The muscle was exercised by plantar flexion of the right ankle, lifting a weight of $10 \%$ lean body mass (determined from skinfold thickness by reference to standard tables ${ }^{9}$ ) a distance of $7 \mathrm{~cm}$ at a rate of $30 \mathrm{~min}^{-1}$. After four 32-scan spectra (1.25 min) had been acquired, the weight was incremented by $2 \%$ of lean body mass for each subsequent spectral acquisition $(1.25 \mathrm{~min})$. The subjects exercised until fatigue prevented them performing the 
Table 1 Exercise performace before and after 6 weeks of creatine or placebo. Values are mean (SEM).

\begin{tabular}{|c|c|c|c|c|}
\hline & $\begin{array}{l}\text { Placebo } \\
\text { pre-Rx }\end{array}$ & $\begin{array}{l}\text { Placebo } \\
\text { post-Rx }\end{array}$ & $\begin{array}{l}\text { Creatine } \\
\text { pre- } R x\end{array}$ & $\begin{array}{l}\text { Creatine } \\
\text { post-Rx }\end{array}$ \\
\hline $\begin{array}{l}\text { Exercise duration in magnet (min) } \\
\text { Performance times (s) } 100 \mathrm{~m} \\
400 \mathrm{~m}\end{array}$ & $\begin{array}{l}13.0(2.6) \\
71.6(2.4) \\
320(10)\end{array}$ & $\begin{array}{l}11.0(1.6) \\
70.6(1.9) \\
318(10)\end{array}$ & $\begin{array}{l}11.3(1.5) \\
73.5(2.4) \\
346(10)\end{array}$ & $\begin{array}{l}10.5(1.6) \\
73.8(1.6) \\
340(6)\end{array}$ \\
\hline
\end{tabular}

$\mathbf{R x}$, treatment

work required. The muscle was then studied for $13 \mathrm{~min}$ during recovery (four 8-scan spectra, four 16-scan spectra, three 32-scan spectra, then two 64-scan spectra). Relative concentrations of $\mathrm{Pi}, \mathrm{PCr}$, and ATP were obtained by a time domain fitting routine (VARPRO, designed by $R$ de Beer, Delft, The Netherlands) and were corrected for magnetic saturation. Absolute concentrations were obtained as described by Arnold et al. ${ }^{10}$ [ATP] was assumed to be $8.2 \mathrm{mM}$ (that is, $\mathrm{mmol}$ litre $^{-1}$ of muscle intracellular water). Intracellular $\mathrm{pH}$ was calculated from the chemical shift of the Pi peak, relative to $\mathrm{PCr} .{ }^{10}$ Free cytosolic [ADP] was calculated from $\mathrm{pH}$ and $[\mathrm{PCr}]$ using the creatine kinase equilibrium constant of $\mathrm{K}_{\mathrm{eq}}=1.66 \times 10^{9} \mathrm{M}^{-1}$, as

$[\mathrm{ADP}]=([$ total creatine $] /[\mathrm{PCr}]-1)[\mathrm{ATP}] /$ $\left(\mathrm{K}_{\mathrm{eq}}\left[\mathrm{H}^{+}\right]\right)$,

assuming a normal total creatine content of $42.5 \mathrm{mM}$. Changes in $\mathrm{pH}$ and $\mathrm{PCr}$ concentration, the latter conveniently expressed as $\mathrm{PCr} /(\mathrm{PCr}+\mathrm{Pi})$, during exercise reveal the adequacy of oxidative ATP synthesis.

Recovery from exercise is a purely oxidative process, and the initial rate of $\mathrm{PCr}$ recovery $(\mathrm{V})$ and the end-of-exercise [ADP] can be used to calculate the maximum rate of oxidative ATP synthesis by the muscle $\left(Q_{\max }\right)$, as

$$
\mathrm{Q}_{\max }=\mathrm{V}\left\{1+\mathrm{K}_{\mathrm{m}} /[\mathrm{ADP}]\right\} \text {, }
$$

assuming the normal value of $K_{m}=30 \mu \mathrm{M} .{ }^{11}$ $\mathrm{Q}_{\max }$ is a measure of the functional mitochondrial capacity of the muscle in vivo. The half

Table $2{ }^{31} \mathrm{P}$ magnetic resonance and near-infrared spectroscopy data from placebo treated and creatine treated subjects. Values are mean(SEM).

\begin{tabular}{|c|c|c|c|c|}
\hline & Placebo pre-Rx & Placebo post-Rx & Creatine pre- $R x$ & Creatine post- $R x$ \\
\hline \multicolumn{5}{|l|}{ Resting muscle } \\
\hline PCr/ATP & $3.2(0.2)$ & $3.4(0.1)$ & $3.1(0.1)$ & $3.3(0.3)$ \\
\hline pH & $7.02(0.01)$ & $7.02(0.01)$ & $7.01(0.02)$ & $7.02(0.01)$ \\
\hline $\mathrm{PCr} /(\mathrm{PCr}+\mathrm{Pi})$ & $0.88(0.01)$ & $0.89(0.01)$ & $0.89(0.01)$ & $0.89(0.01)$ \\
\hline ADP $(\mu \mathrm{M})$ & $18(4)$ & $14(3)$ & $19(2)$ & $16(5)$ \\
\hline $\begin{array}{l}\text { Gastrocnemius } \\
\text { creatine/choline }\end{array}$ & $0.93(0.10)$ & $0.97(0.07)$ & $0.91(0.05)$ & $1.09(0.16)$ \\
\hline $\begin{array}{l}\text { Soleus } \\
\text { creatine/choline }\end{array}$ & $0.98(0.09)$ & $1.05(0.07)$ & $0.97(0.09)$ & $1.01(0.1)$ \\
\hline \multicolumn{5}{|c|}{ Initial exercise spectrum } \\
\hline $\mathrm{pH}$ & $7.07(0.01)$ & $7.08(0.01)$ & $7.08(0.01)$ & $7.08(0.02)$ \\
\hline $\mathbf{P C r} /(\mathbf{P C r}+\mathbf{P i})$ & $0.71(0.03)$ & $0.75(0.02)$ & $0.74(0.03)$ & $0.74(0.02)$ \\
\hline $\mathrm{ADP}(\mu \mathrm{M})$ & $38(7)$ & $31(5)$ & $41(7)$ & $33(5)$ \\
\hline \multicolumn{5}{|l|}{ End exercise spectrum } \\
\hline pH & $0.32(0.04)$ & $0.31(0.03)$ & $0.32(0.03)$ & $0.29(0.03)$ \\
\hline $\begin{array}{l}\mathrm{PCr} /(\mathrm{PCr}+\mathrm{Pi}) \\
\mathrm{ADP}(\mu \mathrm{M})\end{array}$ & $\begin{array}{l}6.60(0.04) \\
57(12)\end{array}$ & $\begin{array}{l}6.58(0.05) \\
57(11)\end{array}$ & $\begin{array}{l}6.60(0.05) \\
55(8)\end{array}$ & $\begin{array}{l}6.58(0.05) \\
63(5)\end{array}$ \\
\hline \multicolumn{5}{|l|}{ Recovery phase } \\
\hline $\mathrm{Q}_{\max }\left(\mathrm{mM} \mathrm{min} \mathrm{min}^{-1}\right)$ & $41(14)$ & $38(11)$ & $30(9)$ & $33(12)$ \\
\hline $\mathrm{PCrt}_{1 / 2}$ (s) & $24(4)$ & $17(2)$ & $35(6)$ & $27(7)$ \\
\hline $\begin{array}{l}\text { Reoxygenation } t_{1 / 2} \\
(s)\end{array}$ & $9(3)$ & $8(3)$ & $10(2)$ & $12(4)$ \\
\hline
\end{tabular}

$\mathbf{R x}$, treatment time of $\mathrm{PCr}$ recovery, assessed from the slope of a semilogarithmic plot, is also a measure of mitochondrial function. ${ }^{10}$

The gastrocnemius and soleus muscles were also examined by proton MRS by means of a STEAM sequence with CHESS water suppression $^{12}$ (mixing time $=30 \mathrm{~ms}$, echo time $=$ $68 \mathrm{~ms}$ ). The volumes of interest $(2 \mathrm{~cm})^{3}$ were selected from the two muscles using a spin echo proton image through the subject's calf (transverse orientation). Eight or 16 scans were accumulated with a repetition delay of five seconds. The ratio of the creatine signal at 3.04 ppm to the choline containing signal at 3.25 ppm was measured using a computer line fitting routine GLINFIT (Bruker, Coventry, UK).

The re-oxygenation rate of the forearm was studied using NIRS. This technique measures the difference in light absorption from the muscle at two wavelengths of light $(760 \mathrm{~nm}$ and $850 \mathrm{~nm}$ ), selected to exploit the difference between oxygenated and deoxygenated haemoglobin. The light source and detectors were placed over the muscle bulk of the finger flexors in the subjects' forearm. Subjects performed a finger flexion protocol lifting a weight of $1.5 \mathrm{~kg}$ at a rate of $40 \mathrm{~min}^{-1}$ for $1 \mathrm{~min}$. After $40 \mathrm{~s}$ exercise, a cuff was inflated about the upper arm to $30 \mathrm{~mm} \mathrm{Hg}$ above systolic pressure. Exercise ceased $20 \mathrm{~s}$ later, the cuff was deflated after a further $5 \mathrm{~s}$, and the half time of the resulting reoxygenation of the arm was used as a measure of the rate of oxygen supply to the recovering muscle.

Data on the same individual were compared using a paired $t$ test. Data between groups on either creatine or placebo were compared using an unpaired $t$ test. Statistical significance was assumed where $\mathrm{P}<0.05$.

\section{Results}

The subjects' lean body mass did not alter over the duration of the study. Neither creatine ingestion nor placebo had any significant effect on exercise duration in the magnet or performance time in the swimming pool (table 1). Swimmers did not report any subjective benefit of placebo or creatine on training performance. Likewise, creatine ingestion had no effect on [ADP], $\mathrm{pH}$, or metabolite ratios in the resting muscle or on changes in these factors during exercise (Table 2). Recovery of muscle oxygenation, resynthesis of $\mathrm{PCr}$, and the calculated maximum mitochondrial ATP synthesis rate following exercise in the magnet $\left(Q_{\max }\right)$ were also unaffected by creatine ingestion (Table 2).

\section{Discussion}

Muscle creatine concentration is determined by a sodium-linked cotransporter that accumulates creatine against a concentration gradient in skeletal muscle. ${ }^{13-14}$ A $55 \mathrm{~kg}$ female has approximately $90 \mathrm{~g}$ of creatine and phosphocreatine in muscle and nerve tissues. ${ }^{15} \mathrm{~A}$ fixed proportion of this $\left(1.7 \% \mathrm{~d}^{-1}\right)$ is excreted in the urine as creatinine.$^{15-16}$ Endogenous biosynthesis and dietary intake of creatine, at a rate of 
$\left(1.5 \% \mathrm{~d}^{-1}\right)$, normally replenishes this pool. Endogenous biosynthesis largely occurs in liver and pancreas and there is some evidence that this can be downregulated by exogenous creatine. ${ }^{16}$ While no formal dietary history was performed on our subjects, no high intake of creatine was present in these subjects before the start of the study. It is possible that the exogenous creatine taken by the athletes in this study did not significantly affect the combined concentrations of creatine and phosphocreatine ([TCr]) because of suppression of the endogenous biosynthesis. Other studies have shown an increase in muscle creatine concentration, particularly in muscle initially deficient in creatine, if higher doses $\left(20 \mathrm{~g} \mathrm{~d}^{-1}\right)$ were given. ${ }^{7}$ This may have increased muscle creatine by a concentration dependent transport mechanism.

\section{RESTING MUSCLE}

As large creatine doses $\left(20 \mathrm{~g} \mathrm{~d}^{-1}\right)$ have been shown not to alter muscle [ATP] ${ }^{7}, \mathrm{PCr} / \mathrm{ATP}$ should remain a valid measure of muscle PCr. This present study showed no changes in resting PCr/ATP, so it is unlikely that [TCr] had changed. Another study noted no significant change in PCr/ATP in resting muscle following creatine ingestion despite an increase in $[\mathrm{TCr}]^{8}$ but the extensive $\mathrm{PCr}$ breakdown inherent in using a muscle biopsy technique (PCr/ATP about 0.45 in that study, compared with 3.3 in the current study) affects interpretation of this ratio in muscle biopsies.

We also used the creatine/choline ratio as an index of alterations in [TCr] in muscle. We failed to see any difference in this ratio in either gastrocnemius or soleus muscle following creatine ingestion. By comparing the first and second study in the placebo treated group, there was no significant training effect on creatine/ choline ratios in these muscles. There was also no relation between the performance time in the swimming pool or in the magnet and the alteration in muscle creatine/choline ratio, suggesting that the changes in muscle creatine were too small to achieve biochemical or physiological significance.

\section{ANAEROBIC METABOLISM}

During initial exercise, muscle metabolism is dominated first by $\mathrm{PCr}$ depletion ${ }^{4}$ and then by the additional production of lactic acid, ${ }^{17}$ both resulting in the generation of ATP anaerobically, and creatine can reduce muscle fatigue during intermittent high intensity exercise, ${ }^{8}$ although the cause of this improvement in muscle function is unclear. Early aerobic exercise is similar to early ischaemic exercise when examined by ${ }^{31} \mathrm{P}$ MRS. ${ }^{17}$ Accordingly, we can use the difference between the resting spectrum and the first exercise spectrum to assess non-oxidative ATP synthesis. These results showed that the initial rates of PCr depletion and glycogenolysis were similar in both groups, implying that creatine ingestion had no effect on anaerobic response of the muscle. The current exercise protocol did not involve intermit- tent exercise and hence the benefit of creatine supplementation to anaerobic metabolism may be limited to high intensity intermittent exercise.

\section{AEROBIC METABOLISM}

In a previous study, creatine supplementation did not have a beneficial effect on endurance (aerobic) exercise. ${ }^{18}$ Recovery of PCr following exercise does not occur in the absence of oxygen supply to the muscle $e^{1920}$ and is reduced in mitochondrial myopathy ${ }^{21}$ and other disorders where mitochondrial function is known to be reduced. ${ }^{11} Q_{\max }$ is a measure of the rate of $\mathrm{PCr}$ recovery after taking into consideration the driving force for $\mathrm{PCr}$ resynthesis, [ADP], and as a result can be used as an index of mitochondrial number and function and muscle oxygen supply. ${ }^{11}$ If creatine had produced an improvement in muscle oxidative capacity by, for example, facilitating the transfer of high energy phosphate between the mitochondrion and the cytosol, we would have expected to see a decrease in PCr recovery half time and an increase in $\mathbf{Q}_{\max }$. Neither differed significantly after treatment with creatine or placebo, implying that neither training nor the additional supplementation of creatine $2 \mathrm{~g}$ daily had any beneficial effect on the oxidative capacity of gastrocnemius muscle of these subjects. It is possible that a muscle more crucial to swimming may have shown different effects of creatine supplementation.

The alterations in performance times in the swimming pool were similar in placebo and creatine treated groups (table 1) reinforcing our ${ }^{31} P$ MRS results that there was no benefit of creatine $2 \mathrm{~g}$ daily. We did not examine the muscles of the arm, which may have shown a different metabolic effect of the creatine supplementation in these athletes.

\section{SUMMARY}

Creatine at a dose of $\mathbf{2} \mathrm{g}$ daily for six weeks had no demonstrable effect on skeletal muscle aerobic or anaerobic metabolism as assessed by ${ }^{31} \mathrm{P}$ MRS. Exercise performance and muscle oxygenation rate were similarly unaffected.

This research was made possible by the financial assistance of the British Heart Foundation and the Medical Research Council of Great Britain. We are grateful to Mr Jennings of AMS Ltd for generous donation of creatine and placebo tablets, to Oxford University Swimming Club for their cheerful and willing participation and to Mrs Y S Green for assistance in performing the near-infrared spectroscopy.

1 Walliman T, Wyss M, Brdiczka D, Nicolay K, Eppenberger HM. Intracellular compartmentation, structure and function of creatine kinase isoenzymes in tissues with high and tion of creatine kinase isoenzymes in tissues with high and fluctuating energy demands: the "phosphocreatine circuit"

for cellular energy homeostasis. Biochem $\mathcal{F} 1992 ; 281: 21-40$ 2 Connett R. Analysis of metabolic control: new insights using a scaled creatine model. Am F Physiol 1988;254:R949-59.
Kemp GJ. Interactions of mitochondrial ATP synthesis phosphorus metabolite concentrations and the creatine kinase equilibrium in skeletal muscle. $f$ Theor Biol 1994;170:239-46.

4 Blei ML, Conley KE, Kushmerick MJ. Separate measures of ATP utilization and recovery in human skeletal muscle. $\mathcal{f}$ Physiol (Lond) 1993;465:203-22.

5 Kemp GJ, Taylor DJ, Styles P, Radda GK. The production, buffering and efflux of protons in human skeletal muscle during exercise and recovery. NMR Biomed 1993;6:73-83.

6 Chasiotis D. The regulation of glycogen phosphorylase and glycogen breakdown in human skeletal muscle. Acta Physiol Scand 1983;suppl 518:1-68.

7 Harris RC, Söderlund K, Hultman E. Elevation of creatine in resting and exercised muscle of normal subjects by creatine supplementation. Clin Sci 1992;83:367-74. 
8 Greenhaff PL, Casey A, Short AH, Harris R, Söderlund K, Hultman E. Influence of oral creatine supplementation on muscle torque during repeated bouts of maximal voluntary exercise in man. Clin Sci 1993;84:567-71.

9 Durnin JVGA, Womersley J. Body fat assessed from total body density and its estimation from skinfold thickness; measurements in 481 men and women aged from 16 to 72 measurements in 481 men and

10 Arnold DL, Matthews PM, Radda GK. Metabolic recovery after exercise and the assessment of mitochondrial function in vivo in human skeletal muscle by means of P-31 NMR. Magn Reson Med 1984;1:307-15.

11 Kemp GJ, Thompson CH, Taylor DJ, Hands LJ, Rajagopalan B, Radda GK. Quantitative analysis by ${ }^{1} \mathrm{P}$ MRS of abnormal mitochondrial oxidative in skeletal muscle during recovery from exercise. NMR Biomed 1993;6:302-10

12 Frahm J, Bruhn H, Gyngell M, Merboldt K, Hanicke W, Sauter R. Localized high resolution proton NMR spectroscopy using stimulated echoes: initial applications to human brain in vivo. Magn Reson Med 1989;9:79-93.

13 Loike JD, Somes M, Silverstein SC. Creatine uptake, metabolism and efflux in human monocytes and macrophages. Am $\mathcal{f}$ Physiol 1986;251:C1 28-35.

14 Odoom JE, Kemp GJ, Radda GK. Control of intracellular creatine concentration in a mouse myoblast cell line [abstr]. Biochem Soc Trans 1993;21:441S.

15 Walker J. Creatine: biosynthesis, regulation, and function. Adv Enzymol 1979;50:177-242.

16 Hoberman H, Sims E, Peters J. Creatine and creatinine metabolism in the normal male adult studied with the aid of isotopic nitrogen. $\mathcal{F}$ Biol Chem $1948 ; 172: 45-58$.

17 Kemp GJ, Thompson CH, Barnes PRJ, Radda GK Comparisons of ATP turnover in human muscle durin ischaemic and aerobic exercise using ${ }^{31} \mathrm{P}$ magnetic resonance spectroscopy. Magn Reson Med 1994;31:248-58

18 Balsom PD, Soderlund K, Ekblom B. Creatine in human with special reference to creatine supplementation. Sports Med 1994;18:268-80.

19 Harris RC, Hultman E, Kaijser L, Nordesjo L-O. The effect of circulatory occlusion on isometric exercise capacity and f Lab Clin Invest 1975;35:87-95.

20 Taylor DJ, Bore PJ, Gadian DG, Radda GK. Bioenergetics of intact human muscle. A ${ }^{31} \mathrm{P}$ nuclear magnet resonance of intact human Mol Biol Med 1983;1:77-94.

21 Taylor DJ, Kemp GJ, Radda GK. Bioenergetics of skeletal muscle in mitochondrial myopathy. $\mathcal{F}$ Neurol Sci 1994;127: 198-206. 